\title{
Microthermal Characterization of Segmented Polyurethane Elastomers and a Polystyrene-Poly(methyl methacrylate) Polymer Blend Using Variable-Temperature Pulsed Force Mode Atomic F orce Microscopy
}

\section{David B. Grandy, ${ }^{\dagger}$ Douglas J . Hourston, ${ }^{\dagger}$ Duncan M. Price, ${ }^{\dagger}$ Michael Reading, ${ }^{, \dagger}$ Glaura Goulart Silva, Mo Song, $^{\dagger}$ and Paul A. Sykes $\$$}

Institute of Polymer Technol ogy and Materials Engineering, Loughborough University, Loughborough, Leicestershire LE 11 3TU, UK; Departmento de Qumica/ ICEx, Universidade Federal de Minas Gerais, CP 702 Pampulha, Belo Horizonte MG 31270-901, Brazil; and Akzo Nobel International Paints Ltd., Protective Coatings Division, Stoneygate Lane, Felling, Gateshead, Tyne and Wear, UK

Received February 3, 2000

\begin{abstract}
Pulsed force mode atomic force microscopy (AFM) has been used to study the morphology of three segmented polyurethane elastomers. High-contrast images are presented, showing their phaseseparated structure on a scale of several tens of nanometers to a few hundred nanometers. The adhesiondependent pull-off force signal is found to be far more sensitive to local variations in mechanical properties than the stiffness-dependent indentation force signal. An insight into the size, shape, and distribution of phases can be obtained from images constructed from spatial variations in surface adhesion properties. Comparison of images obtained both above and below the $T_{g}$ of the soft-segment material allows the spatial distribution of different phases to be characterized and the effects of surface topography to be decoupled from real changes in localized mechanical properties. Typical domain sizes are found to be at least an order of magnitude larger than those obtained by small-angle X-ray scattering and AFM in previous studies. A novel method of constructing and interpreting AFM images of multiphase materials is used. The equipment and methodology are first demonstrated on a model polystyrene-poly(methyl methacrylate) blend.
\end{abstract}

\section{Introduction}

Pulsed force mode (PFM) $)^{1-3}$ is a recent addition to the range of atomic force microscopies (AFM). It is a method of mapping surfaces using measurements related to local adhesion, elastic, and electrostatic properties. Other AFM modes are able to produce images based on mechanical property measurements: phase detection microscopy (PDM), ${ }^{4-12,33}$ force modulation microscopy (FMM), and layered imaging (LI), ${ }^{13}$ for example. Like PDM, PFM is an intermittent contact (IC) mode and shares its advantages of low contact time and low lateral forces acting between the probe and sampleimportant when imaging relatively soft materials. PDM images can be difficult to interpret, because any contrast is dependent on the simultaneous action of elastic, viscoelastic, adhesion, and electrostatic properties of a surface, in conjunction with machine variables, such as the geometry of the probe tip and the driving amplitude of the cantilever. ${ }^{8-12}$ PF M, in theory, offers a more direct and interpretable measurement of mechanical properties. In practice, in common with PDM and other AFM modes, results are affected by factors such as tip and surface geometry. In this study we propose a possible approach to overcoming these difficulties, at least in part by using temperature as a variable.

In PFM the driving frequency remains constant, while in PDM the driving signal must be retuned to a different resonant frequency each time the temperature is changed. This has the disadvantage that another vari-

${ }^{\dagger}$ Loughborough University.

‡ Universidade Federal de Minas Gerais.

$\S$ Akzo Nobel International Paints Ltd.

* Corresponding author. Tel +44 (0)1509 223332; Fax +44 (0)1509 223949; E-mail M.Reading@ boro.ac.uk. able, in addition to temperature, is introduced into each set of data. Furthermore, in this study, the time required for retuning (several minutes) posed a problem, because of the limited time available to us for imaging at $-50{ }^{\circ} \mathrm{C}$ (an inconvenience resulting from the design of our current temperature stage that should be remedied in the near future). Nevertheless, we anticipate that further work will demonstrate that PDM, perhaps using the distance-sweep approach, can provide similar information to that obtained here using PFM.

In both PFM and LI, images are constructed from a sequence of force versus distance curves (FDC), ${ }^{14}$ as the probe tip is driven into the sample surface and then retracted. This process is repeated while the probe is raster scanned over the surface of the sample during image acquisition. In LI, the whole of the force-distance curve is digitized, and each cycle corresponds to a single pixel in the final image. This demands considerable data processing power and scanning to be relatively slow. In PFM, however, the only data points recorded for each cycle are the maximum positive (compressive) force and the maximum adhesive (tensile) force. This greatly reduces the quantity of data to process. A sinusoidal modulation, typically between $100 \mathrm{~Hz}$ and $2 \mathrm{kHz}$, applied to the z-piezocrystal of the AFM scanner, dictates the measurement frequency. This means that, at a given driving frequency, the number of measurement cycles that contribute to a pixel is dependent on the resolution (the total number of pixels) required in the final image (usually a minimum of $300 \times 300$ ). The maximum raster frequency is generally $1 \mathrm{~Hz}$, which gives scan speeds comparable with those of other intermittent contact techniques. The amplitude is within the range $10-300 \mathrm{~nm}$. The frequency of modulation is at least an order of magnitude less than the natural 
frequency of a low spring constant cantilever. The maximum compressive load is typically 5-10 nN. Images are derived from surface topography, indentation force (related to the local stiffness of the material), and the pull-off force signals (related to local adhesion properties). The discrete vertical measurement cycles ensure that contributions from frictional forces are minimized.

This work is divided into two parts. In the first, a model system, a blend of polystyrene (PS) and poly(methyl methacrylate) (PMMA), is used to explore the concept of using changes in temperature to aid the elucidation of structure when making local property measurements by PFM. On a large scale (typically, a few cubic millimeters), thermal analysis is often used to characterize and identify polymers. ${ }^{15}$ Carrying out localized property measurements at different temperatures offers the possibility of applying the same approach on a nanoscale. This principle has already been demonstrated with the introduction of microthermal analysis, ${ }^{16-21}$ which normally utilizes an independently heated probe. The resolution of this technique is, however, limited by the relatively large size of the probe (compared with AFM tips). This results in a minimum of several cubic micrometers of material being sampled. While this limitation will undoubtedly be removed, as smaller probes become available, a simple alternative route to achieving better resolution is to use a conventional AFM tip while heating or cooling the entire sample. Some preliminary results using scanning local acceleration microscopy (SLAM) have already been presented. ${ }^{22}$ In this study, primary and secondary dynamic mechanical transitions were detected successfully by varying the scanning temperature, and some contrast in images was achieved. We have also presented preliminary results from the use of PFM with a variable temperature stage, ${ }^{26,27}$ while, more recently, others have used variable temperature layered imaging. ${ }^{28}$ The use of scanning probe microscopies in conjunction with a variable temperature stage to characterize thermally induced changes in microstructure is clearly valuable and has been demonstrated by several workers. ${ }^{19,29}$ However, this is not the objective of the approach described in this study. Here, we seek to identify phases by investigating how their mechanical properties change with temperature, which necessitates that the structure does not change significantly over the chosen temperature range. These previous studies, together with the data presented here, suggest that there is significant potential in using this method of microthermal characterization as a tool for understanding the properties and structure of polymeric materials.

Many polymer systems are stable over a wide range of temperatures and so are amenable to study in this way. One such material is the PS-PMMA blend chosen here. It is completely phase-separated and remains so at elevated temperatures. Domain sizes can be of the order of tens of nanometers, well below the resolution of the microthermal probes currently available commercially. For these reasons, the system represents a suitable test sample.

In the second part of this study, three elastomeric segmented polyurethane (SPU) samples are investigated. Numerous studies have been published on the morphology of such materials, ${ }^{34-48}$ in which small-angle X-ray scattering (SAXS) and other methods have been used to characterize their phase-separated structure.
These typically reveal domain sizes of the order of 5-25 $\mathrm{nm}$. Characterization of their morphology through more established microscopy techniques, the most obvious being transmission el ectron microscopy (TEM), is difficult, because the different domains produce little contrast in electron density, even after staining. ${ }^{31} \mathrm{~A}$ method of overcoming this problem is through the use of el ement-specific electron microscopy. ${ }^{32}$ This is, however, for this application, a fairly specialized technique. These materials were, therefore, considered to provide a suitable challenge for PFM.

In an IC-AFM study of a solution-cast SPU elastomer, McLean and Sauer ${ }^{33}$ obtained results showing separate hard- and soft-segment domains. A PDM image is shown, revealing a relatively uniform distribution of hard-segment domains 5-10 nm in diameter. Optical microscopy and small angle light scattering (SALS), on the other hand, have identified phase separation on the scale of several micrometers. ${ }^{40,43}$

The principal aims of the current study are as follows: (1) to determine the feasibility and the effects of carrying out pulsed force mode AFM at temperatures substantially above and bel ow room temperature; (2) to investigate the effects of the glass transition on PFM results for a model system and whether the behavior can be used to elucidate structure and identify phases; (3) to investigate the ability of variable-temperature PFM to characterize phase-separated segmented polyurethane elastomers; and (4) to compare the information produced by PFM on the morphology of SPUs with that published in the literature for similar materials obtained by other modes of AFM or unrelated techniques, such as SAXS.

\section{Experimental Section}

Materials. Polystyrene and poly(methyl methacrylate) were obtained from the Aldrich Chemical Co. Ltd. Their weightaverage molecular weight $\left(\mathrm{M}_{\mathrm{w}}\right)$ and polydispersity index $\left(\mathrm{M}_{\mathrm{w}} /\right.$ $M_{n}$ ) were determined by gel permeation chromatography (GPC) to be as follows. PS: $M_{w}=2.40 \times 10^{5} \mathrm{~g} \mathrm{~mol}^{-1}, \mathrm{M}_{\mathrm{w}} / \mathrm{M}_{\mathrm{n}}$ = 4.9; PMMA: $M_{w}=1.03 \times 10^{5} \mathrm{~g} \mathrm{~mol}^{-1}, \mathrm{M}_{\mathrm{w}} / \mathrm{M}_{\mathrm{n}}=2.5$. A 50/ 50 , by weight, blend of PS and PMMA was spun-cast from solution in chloroform onto a glass slide. Thin films of the individual polymers were prepared in the same way. The samples were conditioned in a vacuum oven at $40{ }^{\circ} \mathrm{C}$ for 1 week to remove residual solvent.

4,4'-Methylenebis(phenyl isocyanate) (MDI) of 98\% purity was obtained from the Aldrich Chemical Co. Ltd. Poly(tetramethylene oxide) glycol (PTMG, Terathane 1000) with an average molecular weight of approximately 1000 was supplied by Du Pont Chemicals. Three different chain extenders were used: (1) 1,3-dihydroxybenzene (98\% purity), (2) 1,4butanediol (99\% pure, as confirmed by ${ }^{1} \mathrm{H}$ NMR spectroscopy), and (3) cis-but-2-ene-1,4-diol (95\% purity). These were all supplied by the Aldrich Chemical Co. Ltd. Sykes ${ }^{30}$ covers the syntheses of the materials in detail. The material chainextended with 1,4-butanediol was prepared by a two-shot process and the other two via a one-shot route. The cure temperature was $80^{\circ} \mathrm{C}$ in each case. The materials were cast in an open mold to form a sheet approximately $3 \mathrm{~mm}$ thick. The materials are translucent, strong, high-modulus elastomers. The free surface, which was relatively smooth and gl ossy to the naked eye, was used for imaging.

Pulsed Force Mode AFM (PFM). A Witec pulsed force module was used (Wissenschaftliche Instrumente und Technol ogie GmbH, Al bert-Einstein-Allee 15, D-89081 UIm, Germany), coupled to a TA I nstruments (TAI) 2990 microthermal analyzer incorporating a ThermoMicroscopes Explorer AFM (TA I nstruments, 109 Lukens Drive, New Castle, DE 19720). A Tektronix TDS 210 oscilloscope was used to monitor the modulated force versus time signal and to set the measure- 
ment points. Samples were mounted on a TAl variable temperature stage, which was positioned on an antivibration table. The temperature of the stage was regulated by a Linkam TP 93 temperature controller, which maintained the sample temperature to within $\pm 0.1{ }^{\circ} \mathrm{C}$. Liquid nitrogen coolant was added to the integral Dewar flask to enable subambient temperature imaging. At the time of writing, the effective operating temperature range of the stage was -60 to $250{ }^{\circ} \mathrm{C}$. At temperatures lower than $-60{ }^{\circ} \mathrm{C}$, there was generally insufficient time after the sample had stabilized, to obtain images with reasonable resolution (i.e., one having a minimum of $300 \times 300$ pixels), before temperature control was lost and the flask required replenishment. It is envisaged that a semiautomatic filling system will solve this problem in the near future. To prevent icing at subambient temperatures, the design of the stage is such that the sample and probe are held in a dry nitrogen atmosphere.

ThermoMicroscopes FIS silicon cantilever probes were used, having a resonant frequency of $23-38 \mathrm{kHz}$, a force constant of $0.2 \mathrm{~N} \mathrm{~m}^{-1}$, and a tip radius of approximately $10 \mathrm{~nm}$. The modulation frequency was set at $500 \mathrm{~Hz}$ and the amplitude at $5 \%$ of maximum. The indentation "force" signal (set point) used was $5 \mathrm{nA}$, and the scan frequency was $1 \mathrm{~Hz}$.

The PS, PMMA, and blend samples were all relatively smooth. Suitable areas for imaging were selected using the optical microscope and television camera, which are integral parts of the microscope. Imaging was carried out at $20^{\circ} \mathrm{C}$ intervals, from room temperature up to $160{ }^{\circ} \mathrm{C}$. At high temperatures, condensation was sometimes observed on the cantilever. No detrimental effect on the measurements was encountered, beyond the need to reposition the laser from time to time to recover a signal from the photodetector.

The SPU samples were rougher, requiring an initial $50 \mu \mathrm{m}$ $\times 50 \mu \mathrm{m}$ scan to identify areas smooth enough for analysis. Once this was achieved, a high-resolution $10 \mu \mathrm{m} \times 10 \mu \mathrm{m}$ scan was carried out. This, in turn, was used to select increasingly smaller and smoother areas down to a minimum of $1 \mu \mathrm{m} \times 1$ $\mu \mathrm{m}$. The original area was then scanned again to check for physical damage to the surface caused by the tip. In cases where comparisons of the same area at different temperatures were required, the subambient temperature scan was carried out first. Care was taken to incorporate a distinctive landmark in the image, so as to enable the same area be located after heating back to room temperature and the inevitable movement of the sample relative to the scanner. Such direct comparisons enable the effects of topography on other images to be evaluated.

Modulated Temperature Differential Scanning Calorimetry (M-TDSC). 49 This was carried out on the SPU samples using a TAl 2920 instrument. Each material was heated from -70 to $200{ }^{\circ} \mathrm{C}$ at a rate of $3{ }^{\circ} \mathrm{C} / \mathrm{min}$. The modulation applied was $\pm 0.5^{\circ} \mathrm{C}$ with a period of $40 \mathrm{~s}$. A twopoint temperature calibration of the cell was carried out using the onset of melting of indium and room temperature as references.

\section{Results and Discussion}

A. PS-PMMA B lend. A collection of images obtained from pull-off force measurements of the blend at various temperatures between 60 and $160{ }^{\circ} \mathrm{C}$ is shown in Figure 1. Topographic images from scans made at 60 and 160 ${ }^{\circ} \mathrm{C}$ are also presented. In general, in this study, it was found that the indentation measurement, unlike the pull-off force, did not provide good discrimination between phases or show a marked dependence on temperature. Consequently, we have concentrated on the pull-off force images. The most striking feature is the large, spatially resolved, periodic increase in pull-off force at high temperature. (The maximum signal increases from approximately 5 to $9 \mathrm{~V}$.) The phaseseparated morphology of the blend is now shown clearly, whereas at $60^{\circ} \mathrm{C}$ there is only a faint indication that
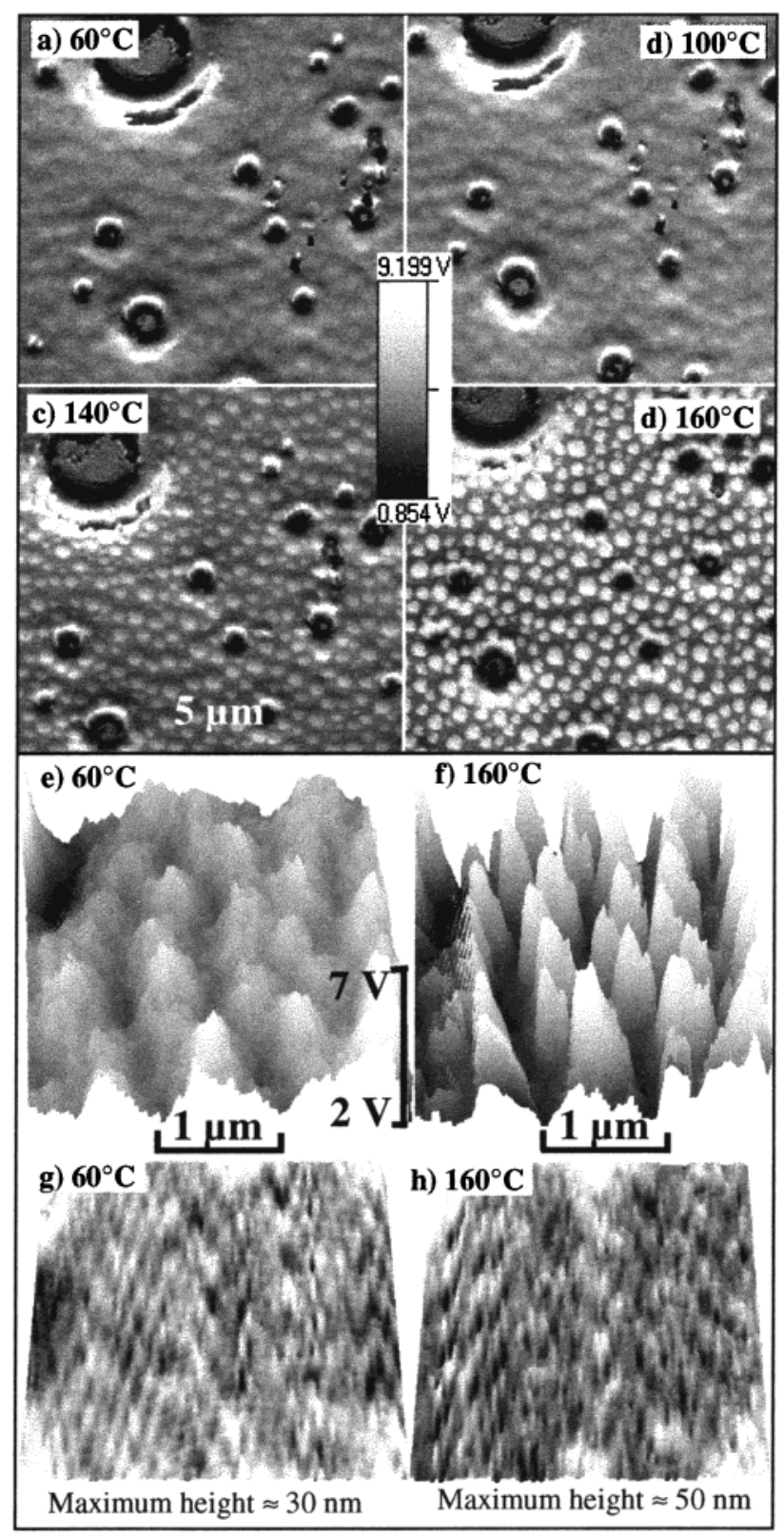

Figure 1. Solution-cast PS/PMMA blend. I mages (a)-(d) map spatial variation in pull-off force at $60,100,140$, and $160^{\circ} \mathrm{C}$, respectively. Lighter shades mean higher force. Here, black corresponds to a signal of approximately $1 \mathrm{~V}$ and white to approximately $8 \mathrm{~V}$. (e) and (f) are $3 \mu \mathrm{m} \times 3 \mu \mathrm{m}$ 3-d "zoom images" from the original $10 \mu \mathrm{m} \times 10 \mu \mathrm{m}$ pull-off force results at 60 and $160{ }^{\circ} \mathrm{C}$. (g) and (h) are the equivalent $3 \mu \mathrm{m} \times 3 \mu \mathrm{m}$ 3-d topographic images at 60 and $160^{\circ} \mathrm{C}$.

such a microstructure exists. These results show that only one of the phases undergoes a significant change in adhesion with temperature. In principle, therefore, characterizing the responses of the individual polymers gives us a way of identifying the different phases. The $3 \mu \mathrm{m} \times 3 \mu \mathrm{m}$ 3-d pull-off force images shown for the two extremes of temperature provide a clear visualization of the magnitude of the increase in adhesion that part of the surface undergoes. The equivalent topographic images show no corresponding change and, therefore, prove that the phenomenon is not a topographic artifact. The softer and more adhesive material at $160{ }^{\circ} \mathrm{C}$ has, however, been roughened and, to some extent, pulled into peaks by the action of the probe.

A series of pull-off force images for PS on glass are shown in Figure 2. It is apparent that there is a 


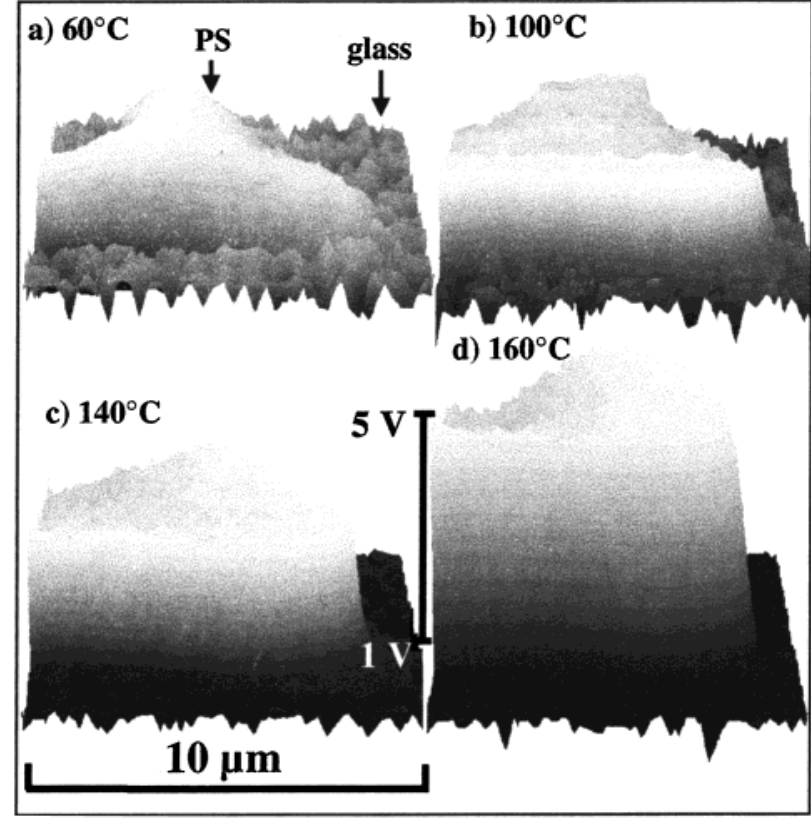

Figure 2. Solution-cast PS on glass. $10 \mu \mathrm{m} \times 10 \mu \mathrm{m} 3-\mathrm{d}$ pulloff force images constructed from $20 \mu \mathrm{m} \times 20 \mu \mathrm{m}$ scans at various temperatures.

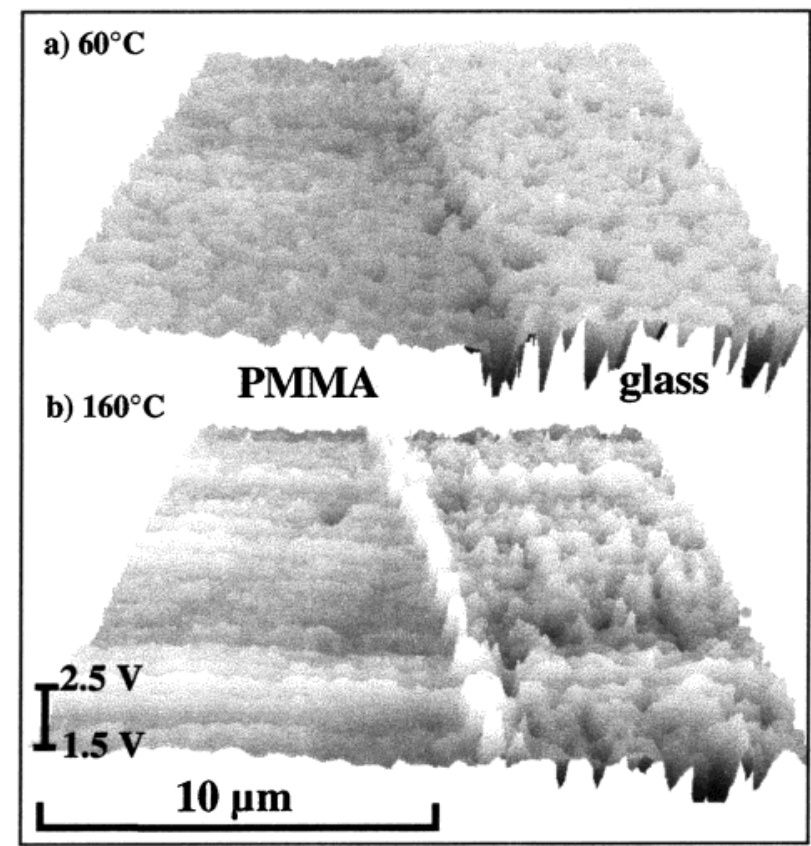

Figure 3. Solution-cast PMMA on glass. The $20 \mu \mathrm{m} \times 20 \mu \mathrm{m}$ 3-d pull-off force images were taken across the edge of a PMMA droplet at 60 and $160{ }^{\circ} \mathrm{C}$.

substantial increase in adhesion between 100 and 120 ${ }^{\circ} \mathrm{C}$, as the material passes through its $\mathrm{T}_{\mathrm{g}}$. By $160{ }^{\circ} \mathrm{C}$, there has been at least a 4-fold increase in pull-off force, compared with the signal at $60^{\circ} \mathrm{C}$. The equivalent results for PMMA on glass, shown in Figure 3, reveal no corresponding increase in adhesion with temperature. In contrast with the PS sample, the spatial distribution of pull-off force appears to be more uniform at high temperature. The probable cause of this is the (topographic) smoothing of the now soft material by the action of the probe. We can therefore conclude that the occluded phase in the blend must be polystyrene In the approach that is illustrated by these results, we rely on the influence of the temperature dominating other

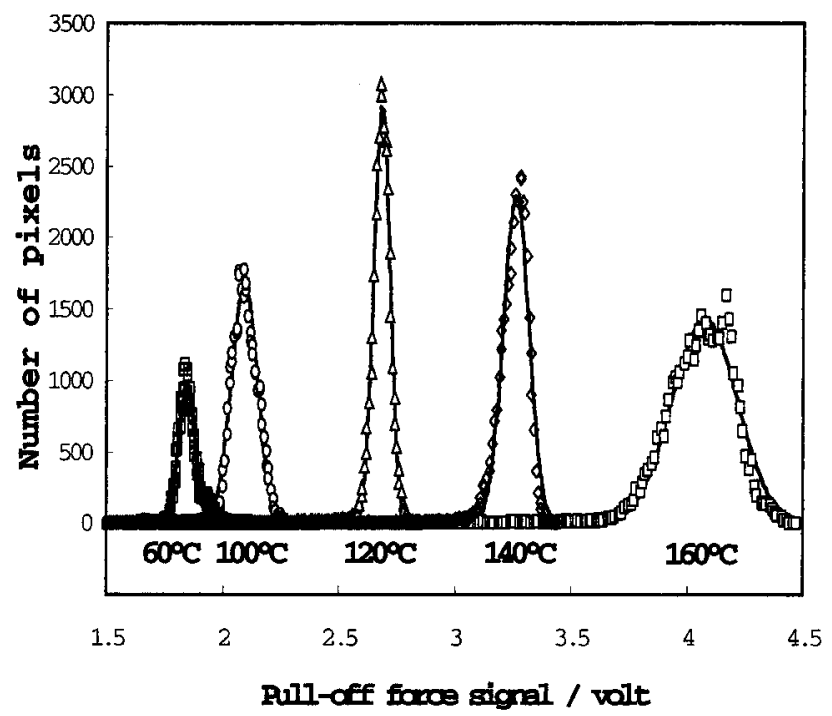

Figure 4. Solution-cast PS. A series of histograms $(10 \mu \mathrm{m} \times$ $10 \mu \mathrm{m}$ sample) showing the variation in pull-off force distribution as a function of temperature. The solid lines are the result of Gaussian curve fitting.

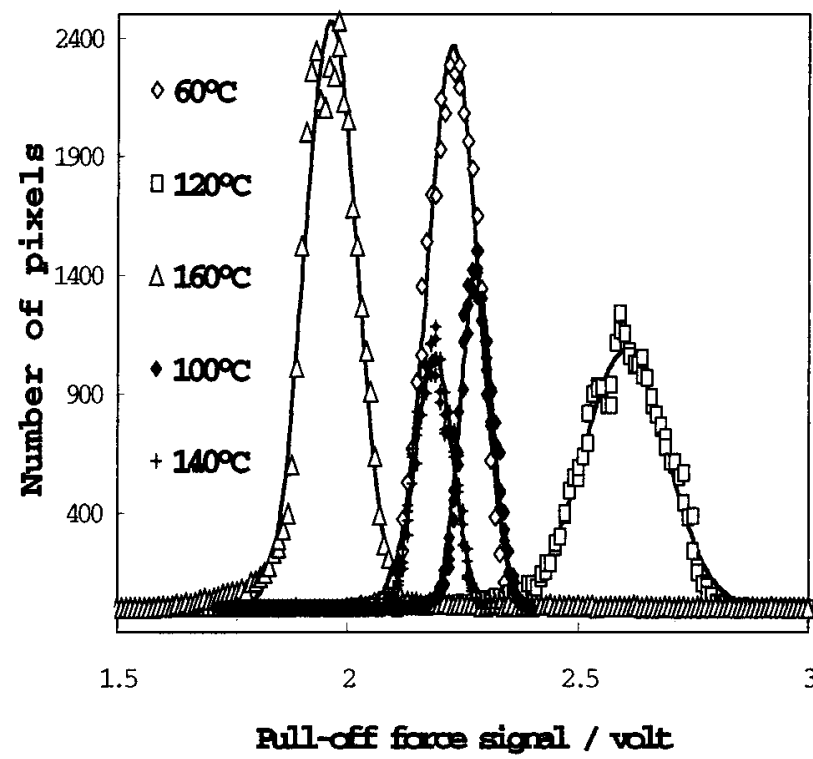

Figure 5. Solution-cast PMMA. A series of histograms (10 $\mu \mathrm{m} \times 10 \mu \mathrm{m}$ sample) showing the variation in pull-off force distribution with temperature. The solid lines result from Gaussian curve fitting.

possible influences, such as sample and tip topography. In this way, informed by the knowledge of how individual components behave with temperature, it is possible to identify phases even though other factors may influence the results and complicate the interpretation of images.

The results for PS and PMMA can be presented as histograms of the number of pixels as a function of pulloff force, as shown in Figures 4 and 5, respectively. These enable us to see clearly the numerical distribution of measurements decoupled from their location on the sample. The mean of the peak for PS steadily increases with temperature, from under $2 \mathrm{~V}$ at $60^{\circ} \mathrm{C}$ to over $4 \mathrm{~V}$ at $160^{\circ} \mathrm{C}$. No such systematic behavior is seen with the PMMA, and the total range between peaks is only around $0.75 \mathrm{~V}$. An important point to note is that a single phase has a distribution of responses, rather than a single value. These distributions are approximately Gaussian, as shown by the curves fitted to the data sets 


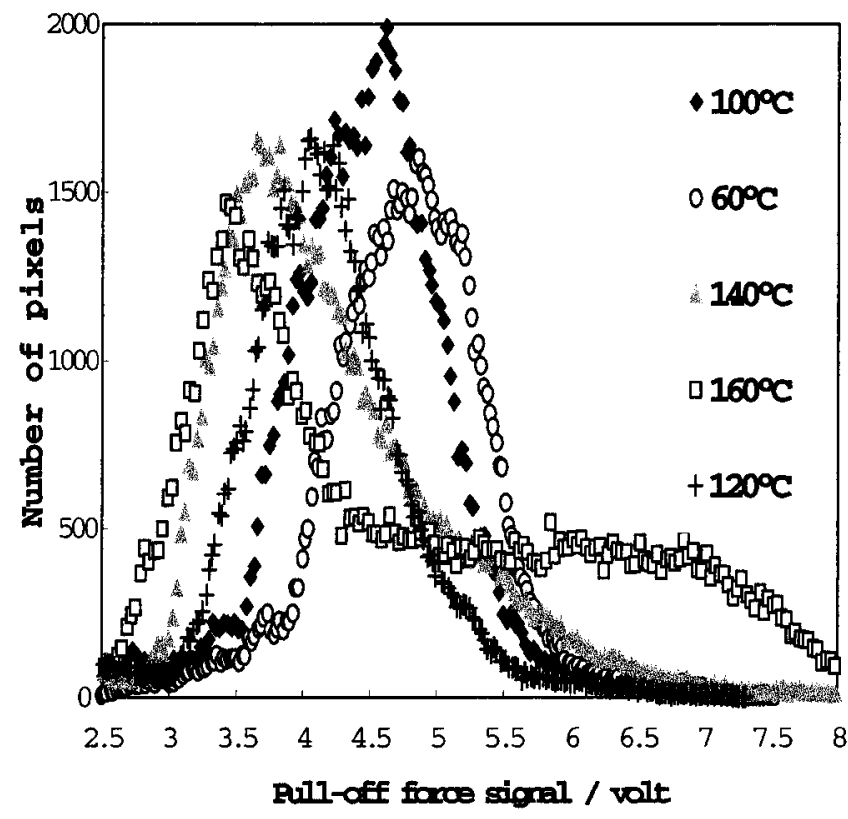

Figure 6. Solution-cast PS/PMMA blend. A series of histograms ( $3 \mu \mathrm{m} \times 3 \mu \mathrm{m}$ area) showing the variation in pull-off force distribution with temperature. For clarity, the results of curve fitting to the data sets have not been included.

in these figures. A distribution of some form is to be expected, as all measurements contain error. It is not clear, however, whether these distributions arise from normal measurement errors. It is likely to be the case that polymeric surfaces have an inherent heterogeneity for this parameter. This point will be discussed further below. Regardless of the origin of these distributions, it is important to note that a single phase gives only one peak. While such a peak may or may not shift significantly with temperature, it will remain monomodal in character. The histograms for the PS-PMMA blend are shown in Figure 6. As the temperature is increased, there is a very clear transformation from a single, approximately monomodal, peak to an approximately bimodal distribution. This reinforces the conclusion drawn above from the pull-off force images. The PS-PMMA system has two distinct phases, and as the temperature is increased, only the pull-off force of the polystyrene shows any significant increase. The images then identify this phase as the occluded one. However, Figure 7, which shows the data for the blend at $160^{\circ} \mathrm{C}$, reveals that at least three separate Gaussian distributions are required to provide an adequate fit to the data set. Before discussing this point, it is necessary to discuss the observation that, at a given temperature, the average pull-off force is significantly higher for the blend than for either of the single polymers.

In these experiments, the pull-off force signal is not calibrated to give a reading in absol ute units of force; it remains expressed in volts. Factors that would affect the relationship between voltage and force include the spring constant of the cantilever, the radius and shape of the tip, the cleanliness of the tip, the reflectivity of the top of the cantilever, and alignment of the laser. In our study, the probe tip required replacing between making the measurements on the blend sample and those carried out on the individual polymer samples. Any of the factors listed above could, therefore, explain the change in the range of observed pull-off force measurements. The problem of calibrating these measurements and allowing for changes in tips due to

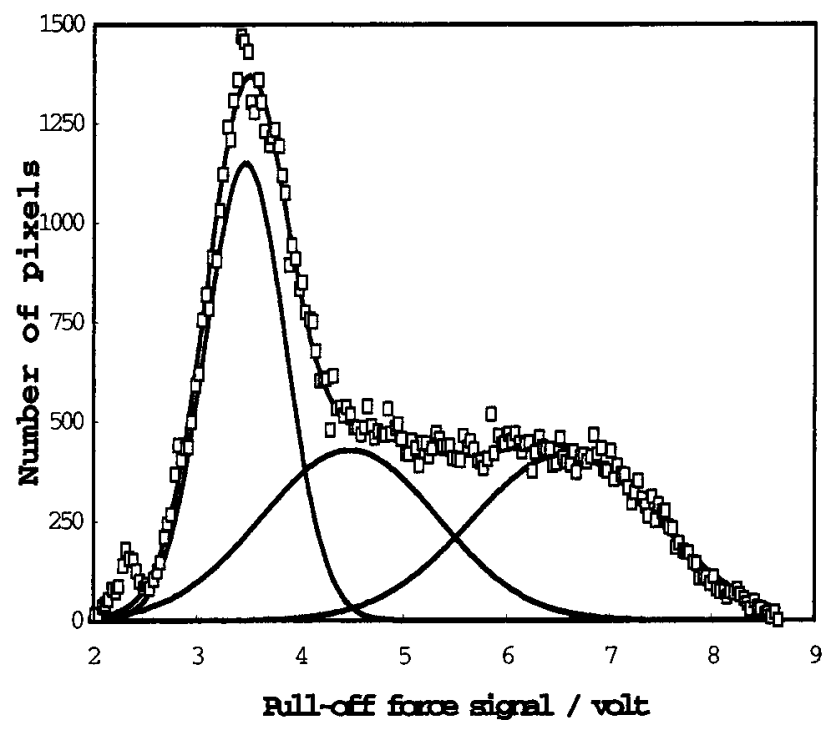

Figure 7. Solution-cast PS/PMMA blend. Histogram ( $3 \mu \mathrm{m}$ $\times 3 \mu \mathrm{m}$ area) showing the pull-off force distribution at 160 ${ }^{\circ} \mathrm{C}$. The results of Gaussian curve fitting are shown as solid lines.

damage or wear is the subject of ongoing work. For the purposes of this report, we must assume that comparisons of absolute values between different series of experiments are unreliable, and we must rely instead on the trends in behavior as a function of temperature.

The reasons why the temperature dependence of the responses of the individual polymers differs so widely are unclear. The nature of the interactions between a polymer surface and probe tip at the nanometer scale is not yet well understood. Work has been done on lower molecular weight organic materials showing good correlation between pull-off force and adhesive force. ${ }^{23}$ Krotil et al. ${ }^{1}$ have made an initial study of the effect of the molecular weight of PS on pull-off force and its dependence on temperature. A tentative conclusion from this work is that pull-off force reduces with increasing molecular weight. The distribution of mol ecular weight across a surface is indeed one factor that may play a role in the form of the distributions obtained in pull-off force values. At lower temperatures, hydrophilic surfaces have been shown 24,25 to exert higher adhesive forces on a chemically neutral tip than hydrophobic materials. If such a mechanism was at work in our study, it may be expected that PMMA, because it is a more polar than PS, would exert greater adhesion on the hydrophilic tip. Our results support no such conclusion. Another factor that will affect the pull-off measurement is the viscoelastic nature of the material. This is consistent with the observation that it changes greatly at the $T_{g}$ for polystyrene but again raises the question of why no such effect is seen with the PMMA. It must be concluded that many mechanisms could affect pulloff force and that further work is required to el ucidate the effects of factors such as molecular weight. Nevertheless, the observation that PS and PMMA have very different behaviors as a function of temperature enables images to be created that, at an appropriate temperature, all ow the different phases to be clearly differentiated and individual phases to be identified. The goal of using temperature to elucidate structure and identify phases on a small scalehas, thus, been achieved in this case.

We now return to the question of why at least three Gaussian peaks are required to fit the pull-off force 


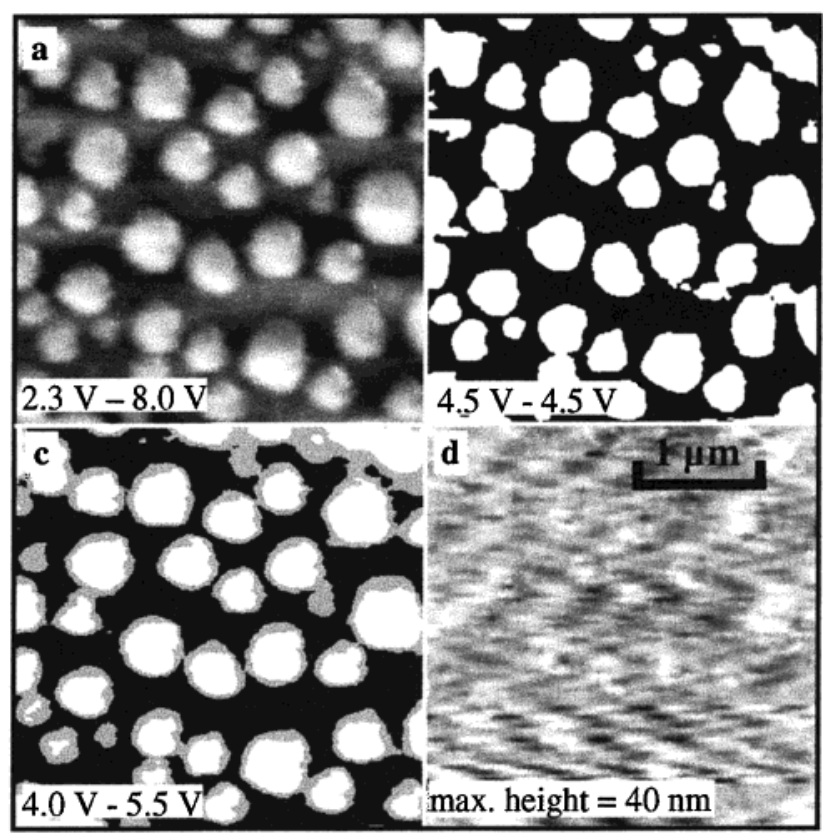

Figure 8. Solution-cast PS/PMMA blend at $160^{\circ} \mathrm{C}$. (a) Pulloff force image with shading graduated over the whole measurement range. (b) The same area as in (a), but with a decision boundary set at $4.5 \mathrm{~V}$, which is the mean of the intermediate peak shown in Figure 7. (c) As (b), but with all results where the intermediate peak in Figure 7 is dominant $(4.0-5.5 \mathrm{~V})$ now resolved as gray pixels. Those pixels with values below this range are black, and those above are white. (d) The corresponding topographic image.

distribution at $160{ }^{\circ} \mathrm{C}$ for the PS-PMMA blend shown in Figure 7. The obvious conclusion would be that there are more than two phases in this system, whereas we believe there are only two. To explain this, we have presented a series of images of the blend in Figure 8. The first (a) is a "conventional" pull-off force image produced with graduated shading over the whol evoltage range. I mage (b) was derived by assuming the existence of a two-phase structure and imposing a threshold, a "decision boundary", at the voltage at which the maximum of the intermediate peak in Figure 7 occurs (4.5 V). All measurements bel ow this value are, therefore, assigned to the PMMA phase and produce black pixels, and all those above are assigned to the PS phase and give white pixels. No gray is allowed. The final pull-off force image (c) was again constructed with the information in Figure 7, but in this case the intermediate peak was assumed to represent a real phase and two thresholds were imposed. All data points that lie in the region where the Gaussian peak with the lowest mean value has the highest intensity $(\leq 4.1 \mathrm{~V})$ have been processed to give black pixels, those where the Gaussian peak with the intermediate mean is highest are gray $(4.1 \mathrm{~V} \leq$ pulloff force $\leq 5.5 \mathrm{~V}$ ), and all those where the Gaussian peak with the highest mean is highest are white $(\geq 5.5 \mathrm{~V})$. In effect, we are assigning the probable phase to each value of pull-off force, commensurate with the phase that has the highest probability of being correct at that value. The resulting image shows that the "intermediate phase" appears around the occluded phase and therefore has the appearance of being an "interphase" with a width of several tens of nanometers. This can be discounted in this case, because these polymers are known to be highly immisible. The topographic image of this region (d) contains no corresponding features. It is unlikely, therefore, that this intermediate phase is a

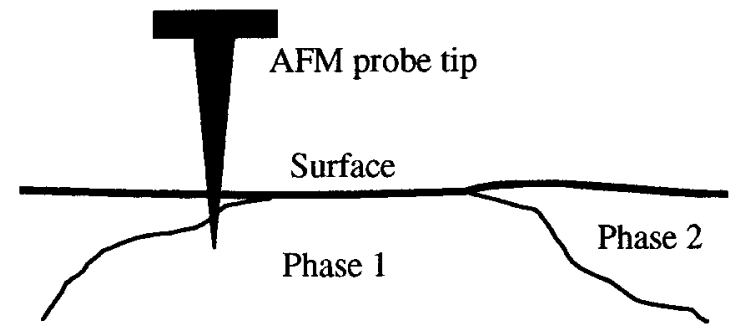

Figure 9. Schematic diagram showing how the subsurface structure of an immiscible phase-separated binary polymer blend could give rise, in PFM pull-off force images, to an apparent third phase surrounding the occluded phases.

topographic artifact. We propose that the explanation is that the structure of the blend changes with depth in the manner shown in Figure 9. At the edges of the occluded phase, as it penetrates the surface, the tip comes into contact with both phases. Because of this, we observe a response that is intermediate to that of the two pure materials. The possible influence of threedimensional structure on the pull-off force images must, therefore, be borne in mind when interpreting them. It should be noted that any interphase cannot real istically be represented by a single Gaussian distribution; at best it is a rather crude approximation. However, in the absence of other information with which to construct an alternative distribution, the fitting of Gaussian peaks would seem to be a reasonable starting point in interpreting pull-off force histograms and enabling the construction of the most meaningful images from them.

B. Segmented Polyurethanes. 1. SPU with 1,3Dihydroxybenzene Chain Extender. Figure 10 shows images obtained at room temperature and $-50{ }^{\circ} \mathrm{C}$ for the material incorporating the 1,3-dihydroxybenzene chain extender. The topographic images confirm that the same area was scanned at the two temperatures and that changes in topography are not responsible for the changes in the other images. Excellent contrast is apparent in the room temperature pull-off force image. A high concentration of occluded domains or phases is revealed, with relatively low surface adhesion, embedded in a relatively high-adhesion continuous phase. The domains range in diameter from under $100 \mathrm{~nm}$ to over $400 \mathrm{~nm}$. This morphology is also reflected in the indentation force image, although with less contrast and detail. (This sample provided the best indentation images encountered in the study.) The low adhesion phases must, therefore, be relatively stiff or hard structures. These presumably incorporate predominantly hard segment material, in the surface layer at least. Their size, however, is at least an order of magnitude greater than that expected for individual hard-segment domains in this type of SPU. As far as the authors are aware, this is the first time that such high-contrast "real space" images have been obtained using a thermally based technique, which show clearly the phase-separated microstructure of a SPU at a scale substantially larger than that of individual domains. At $-50{ }^{\circ} \mathrm{C}$, the contrast all but disappears, because the continuous phase is now much less adhesive toward the tip. There is, however, a feature toward the top of the image (b) with relatively high pull-off force, though still considerably lower than the average value of the continuous phase at room temperature. Inspection of the corresponding topographic image, (f), shows that this feature is related to a high region and is probably, therefore, caused by the topography. The fact that this 


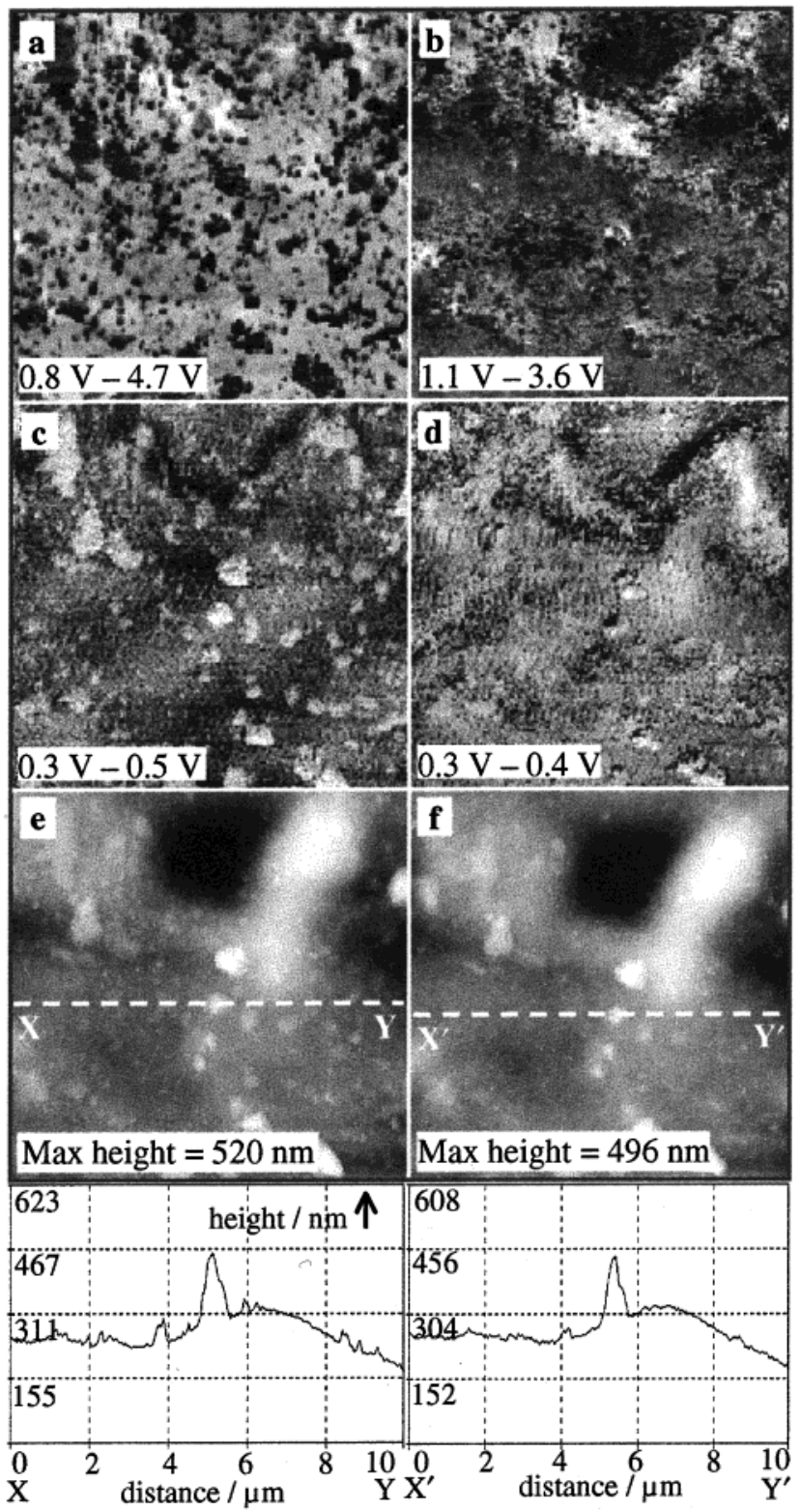

Figure 10. Chain extender: 2,3-dihydroxybenzene. The 10 $\mu \mathrm{m} \times 10 \mu \mathrm{m}$ scans of the same area at room temperature (left) and $-50^{\circ} \mathrm{C}$ (right). (a) and (b) show spatial variation in pulloff force at the two temperatures, (c) and (d) are constructed from the indentation force, (e) and (f) show topography, and $(g)$ and $(h)$ are topographical sections. Dark areas indicate low values in each case

artifact is swamped by the effect of changing the temperature is evidence that supports the utility of the approach advocated in this article. The indentation force image still suggests that the occluded domains are marginally stiffer than the surrounding material. The M-TDSC results in Figure 11 show that, on heating, this material undergoes a glass transition that finishes at approximately $-42{ }^{\circ} \mathrm{C}$. This is the only transition between $-50{ }^{\circ} \mathrm{C}$ and room temperature and occurs in the soft segments of the polyurethane chains. This result, combined with the images at above and below the onset of the glass transition, therefore serves to identify the phase that is bright at room temperature as being soft segment-rich. In this case, and all of those dealt with in this study, at the lower temperature of $-50{ }^{\circ} \mathrm{C}$, the soft segment is not beneath the onset of its glass transition, but is some way into it as measured by M-TDSC (see Figure 11). However, the M-TDSC

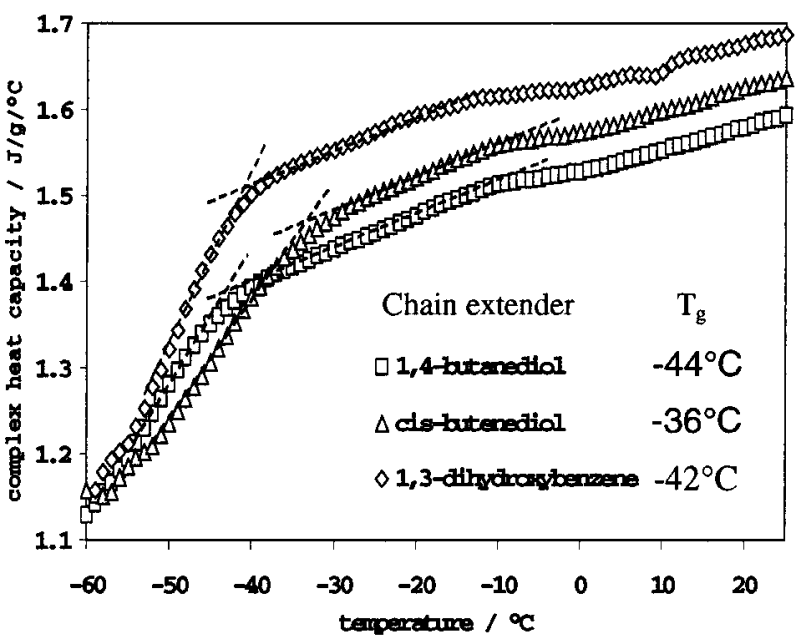

Figure 11. M-TDSC results for the segmented polyurethanes.

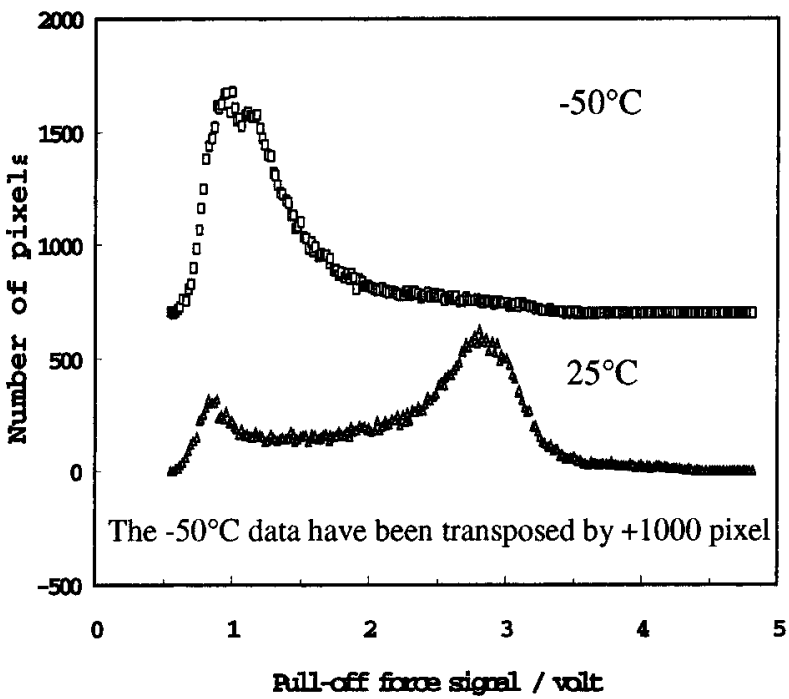

Figure 12. Chain extender: 1,3-dihydroxybenzene Histograms showing the pull-off force distribution at room temperature and $-50{ }^{\circ} \mathrm{C}$. A $10 \mu \mathrm{m} \times 10 \mu \mathrm{m}$ scan.

measurement was carried out at $0.025 \mathrm{~Hz}$, whereas the PFM measurements were made at $500 \mathrm{~Hz}$. This difference in frequency will tend to make the glass transition, as seen by PFM, significantly higher than that detected by M-TDSC. This should, therefore, enhance our ability to detect the effect of the transition on PFM measure ments.

The occluded hard domains are shown in the topographical images to be higher than the surrounding continuous phase. The line measurement sel ected from the room temperature image shows that they range in height from approximately 20 to $150 \mathrm{~nm}$ above the average level of the continuous phase. Some topographical contrast is lost at $-50^{\circ} \mathrm{C}$. A possible explanation for this is that the, now glassy, soft segment material is no longer deformed to the same extent by the compressive stresses imparted by the tip during the indentation part of the measurement cycle. This would be consistent with the indentation images.

Looking at the histograms of the pull-off force images in Figure 12, we see a virtually monomodal distribution at low temperatures changing to a well-differentiated bimodal distribution at room temperature. The material that has formed the higher pull-off force peak at room temperature is presumably the material that has passed 


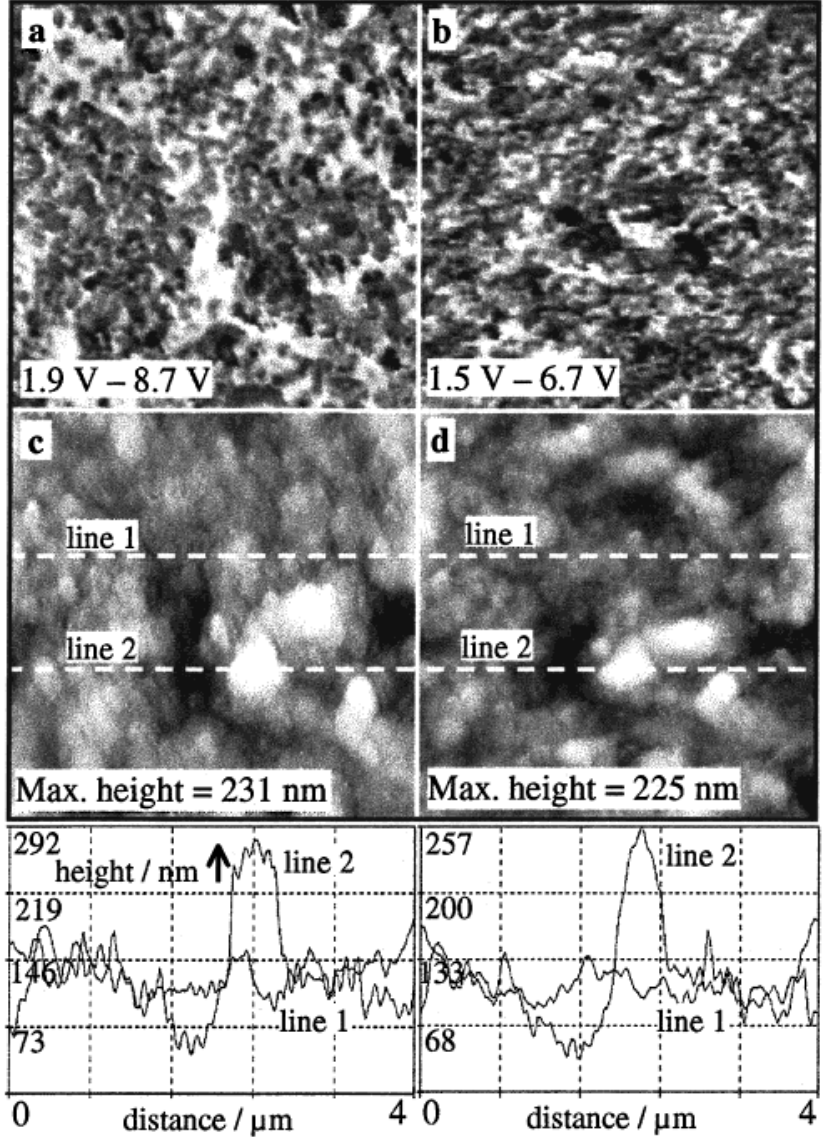

Figure 13. Chain extender: 1,4-butanediol. The $4 \mu \mathrm{m} \times 4$ $\mu \mathrm{m}$ details of the same area of a $10 \mu \mathrm{m} \times 10 \mu \mathrm{m}$ image, showing pull-off force (a) and (b) and topography (c) and (d) at room temperature (left) and $-50{ }^{\circ} \mathrm{C}$ (right).

through its glass transition. This corresponds to the continuous phase. This behavior echoes that seen for the PS-PMMA blend, except the differentiation between the two phases at higher temperatures is even more marked.

2. SPU with 1,4-Butanediol Chain Extender. Figure 13 shows $4 \mu \mathrm{m} \times 4 \mu \mathrm{m}$ images extracted from a $10 \mu \mathrm{m} \times 10 \mu \mathrm{m}$ scan of the material chain-extended with 1,4-butanediol. Even at this higher level of magnification, the structure is too fine to be able to make realistic estimates of the size and distribution of phases. This indicates that the phase-separated morphology is on a finer scale than in the first material (see Figure 10). There is an increase in the maximum pull-off force signal, from $3.2 \mathrm{~V}$ at $-50{ }^{\circ} \mathrm{C}$ to $7.2 \mathrm{~V}$ at room temperature (3.2-8.4 V in the original $10 \mu \mathrm{m} \times 10 \mu \mathrm{m}$ scan). This again shows that the adhesion properties of at least part of the surface undergo a marked change at some intermediate temperature. M-TDSC shows (Figure 11) that this sample has a glass transition finishing, on heating, at $-44^{\circ} \mathrm{C}$. When we examine the pull-off force histogram, shown in Figure 14, we again see a shift from a near monomodal distribution to a clear bimodal distribution, as a consequence of passing through the transition temperature.

There is more detail in the topographic image taken at room temperature than that taken at $-50^{\circ} \mathrm{C}$. This is confirmed in the equival ent line measurements. This observation is most likely to be associated with the increase in compressive modulus of the softer phase below its $T_{g}$. (In most polymers, increases of 2 orders of

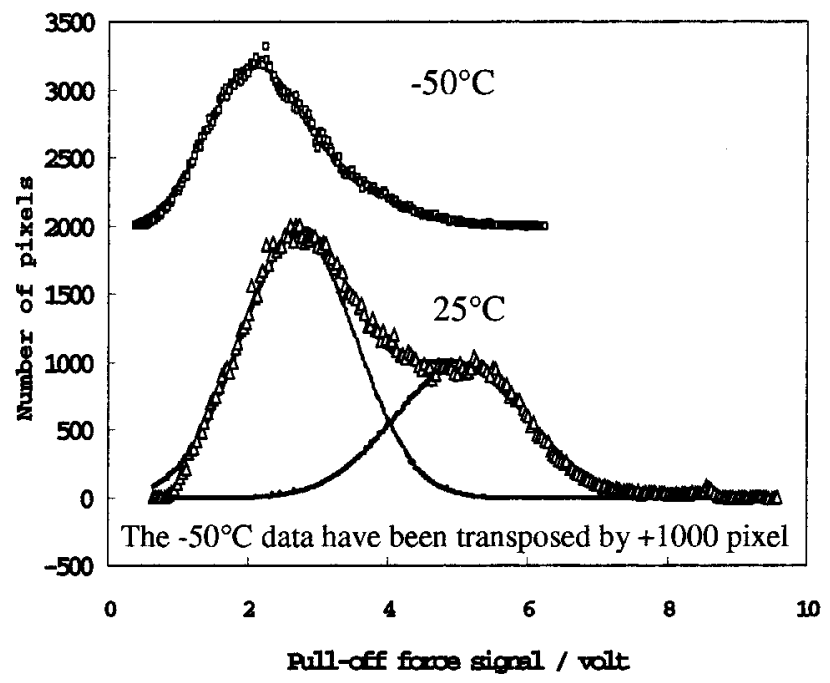

Figure 14. Chain extender: 1,4-butanediol. Histograms from a $10 \mu \mathrm{m} \times 10 \mu \mathrm{m}$ scan, showing the pull-off force distribution at room temperature and $-50^{\circ} \mathrm{C}$. The results of curve fitting are shown for the bimodal distribution obtained at room temperature.

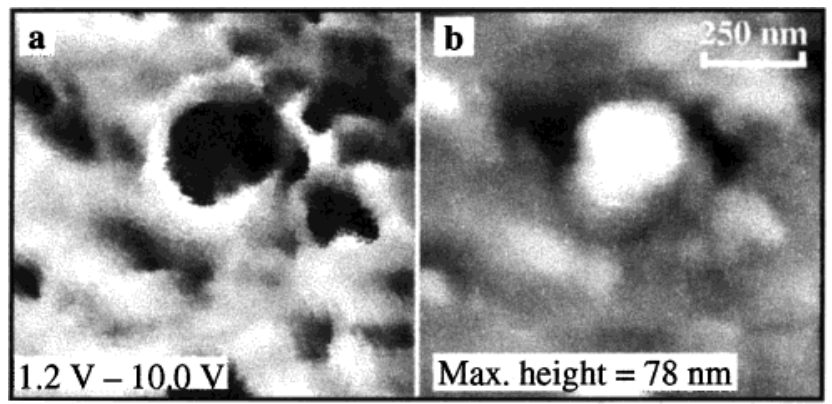

Figure 15. Chain extender: 1,4-butanedi ol. Pull-off force (a) and topographical (b) images from a $1 \mu \mathrm{m} \times 1 \mu \mathrm{m}$ scan made at room temperature.

magnitude may be expected.50) This is consistent with the observations made above on the sample with the 1,3-dihydroxybenzene chain extender.

Because of the fine structure apparent in this material, a series of $1 \mu \mathrm{m} \times 1 \mu \mathrm{m}$ scans were carried out. Typical adhesion and topographic images are shown in Figure 15. A complex morphology is apparently revealed. Low-adhesion (dark) lobe-shaped phases are distributed through a high-adhesion (light to gray) continuous phase and typically range in diameter from 100 to $300 \mathrm{~nm}$. The lobelike shape of the phases is unlikely to be an artifact, because it was reproduced in scans of the same area at different magnifications. The occluded low-adhesion phases are higher than the surrounding continuous phase. At the time of writing, the $1 \mu \mathrm{m} \times 1 \mu \mathrm{m}$ scan was at the limit of the capabilities of our AFM scanner. For this reason, we could not attempt to resolve any structural detail within individual phases.

The gray (intermediate adhesion) regions in the highmagnification pull-off force images will be formed, in part, by the overlap in the pull-off force distributions for the two populations of domains present in this sample, as shown in Figure 14. We noted above, in the discussion of the PS sample, that even a "pure" phase gives an approximately Gaussian distribution of re sponses. This sample displays incompletely separated Gaussian peaks, although, unlike the PS-PMMA blend sample, two Gaussian distributions are all that are 


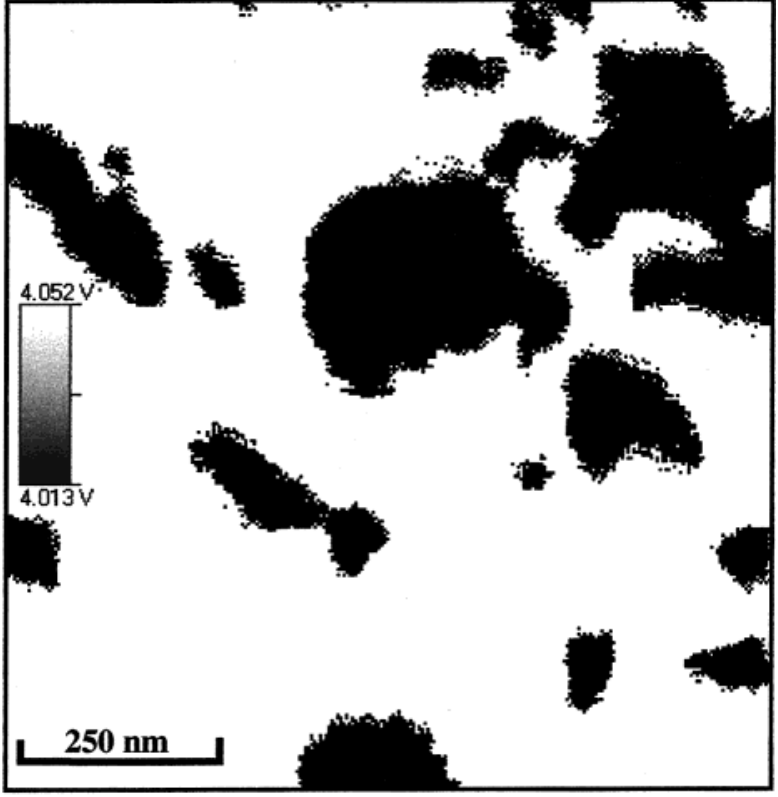

Figure 16. Chain extender: 1,4-butanediol The $1 \mu \mathrm{m} \times 1 \mu \mathrm{m}$ room-temperature pull-off force image in Figure 15, processed using the curve-fitting information in Figure 14. All measurements below the intersection voltage of the two populations (4.1 V) give black pixels, and all those above give white.

required to achieve a good fit to the data. It foll ows that, in the overlapping region of pull-off force, this parameter cannot be used to distinguish between the different phases, because of the distribution inherent in the measurement. This is true even if there are, in reality, only two distinct, completely spatially separated phases. Consequently, a detailed interpretation of the images is complicated. It will depend on whether the distribution is purely random or arises as a consequence of topography (at worst, a second-order effect here), the quality of feedback control (itself dependent on topography), a "real" spatial distribution of adhesion properties at the surface, and possibly many other factors. Appropriate methods of image analysis will be dealt with in a future publication. Here the simple approach adopted above for the PS-PMMA blend is again used. All those data points with values in the area where the Gaussian peak with the lower mean has the higher value are shown as black and all others as white. This treatment is applied to the pull-off force image from Figure 15 to produce Figure 16.

In summary, Figure 14 suggests that there are only two phases present on the surface of this sample, whereas inspection of the images in Figure 15 gives the impression that many phases might be present, because shapes with various shades of gray can be discerned. We propose that the latter observation is an illusion that arises from the inherent distribution in pull-off force produced by even a pure phase. When these distributions overlap, some strategy is required to interpret the image correctly. Here we have used a very simple strategy to obtain Figure 16, but this map of the distribution of the phases will be approximately correct. The blurring apparent around the edges of the dark phases implies that this is where the uncertainty lies.

3. SPU with cis-But-2-ene-1,4-diol Chain EXtender. Figure 17 shows $4 \mu \mathrm{m} \times 4 \mu \mathrm{m}$ "zoom" images taken from a $10 \mu \mathrm{m} \times 10 \mu \mathrm{m}$ scan of the material chainextended with cis-but-2-ene-1,4-diol. Once more, there is still insufficient magnification to reveal precise

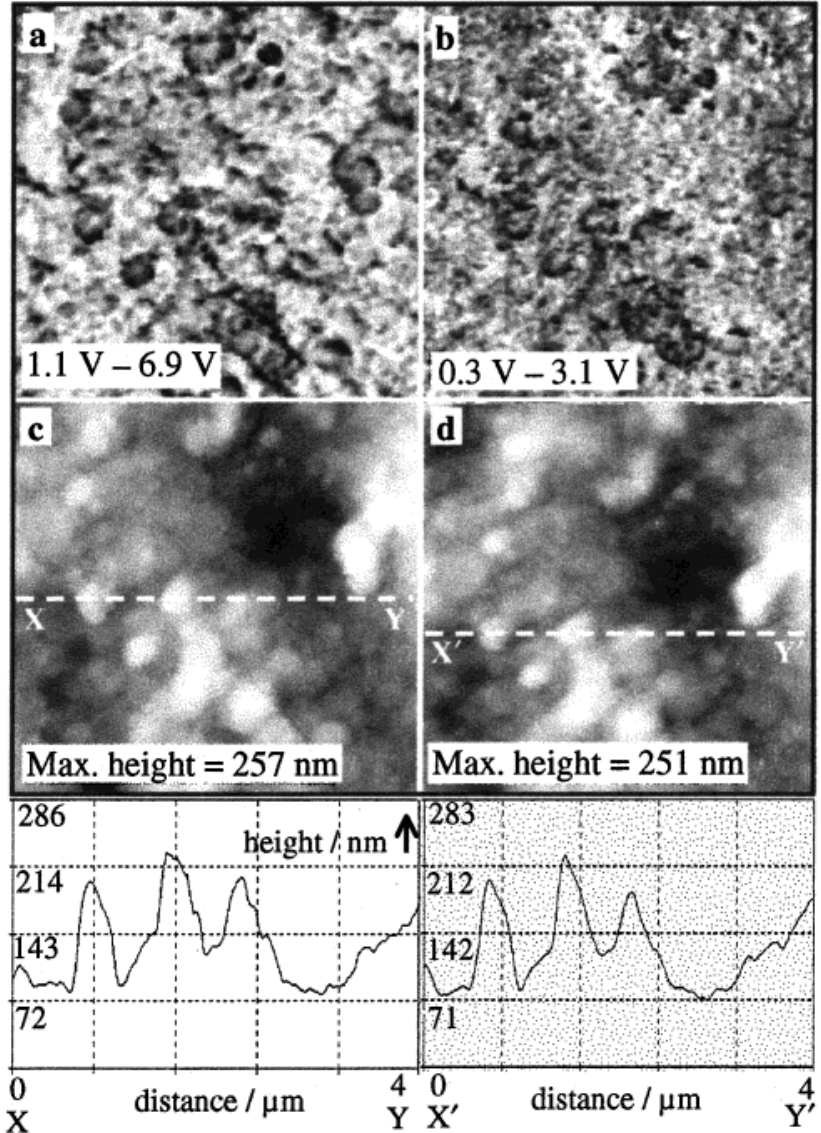

Figure 17. Chain extender: cis-but-2-ene-1,4-diol. The $4 \mu \mathrm{m}$ $\times 4 \mu \mathrm{m}$ details of the same area of a $10 \mu \mathrm{m} \times 10 \mu \mathrm{m}$ image, showing pull-off force (a) and (b) and topography (c) and (d) at room temperature (left) and $-50{ }^{\circ} \mathrm{C}$ (right).

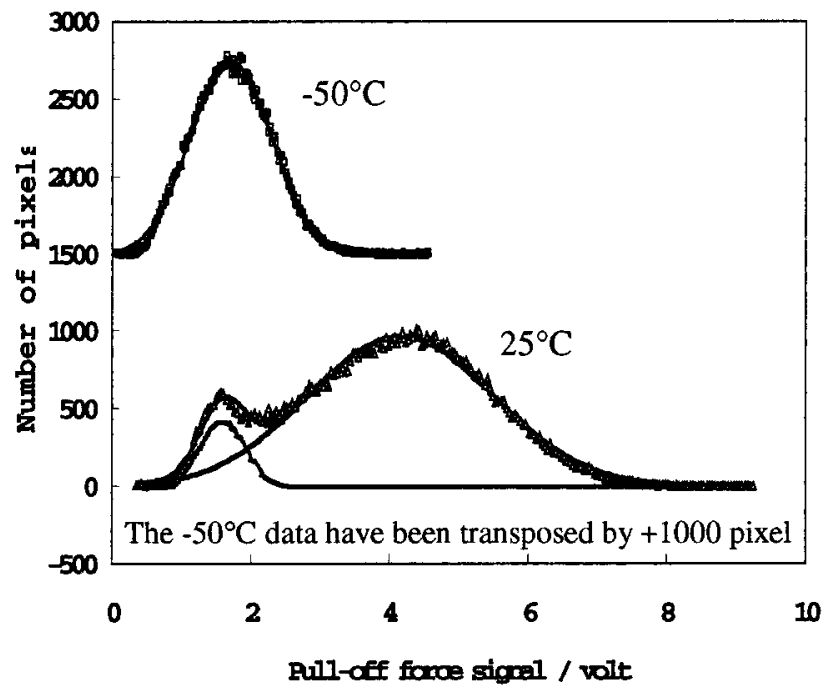

Figure 18. Chain extender: cis-but-2-ene-1,4-diol. Histograms from $10 \mu \mathrm{m} \times 10 \mu \mathrm{m}$ scans, showing the pull-off force distribution at room temperature and $-50^{\circ} \mathrm{C}$. The results of curve fitting are shown for the bimodal distribution obtained at room temperature.

morphological information. However, changing the temperature results in a shift in pull-off force range from 3.4 to $8.4 \mathrm{~V}$. Similarly, the histograms for the $10 \mu \mathrm{m} \times$ $10 \mu \mathrm{m}$ sample in Figure 18 show a transformation from a near monomodal peak at low temperature to a clear bimodal distribution at room temperature. As before, this indicates that part of the material undergoes a transition within this temperature range. M-TDSC 


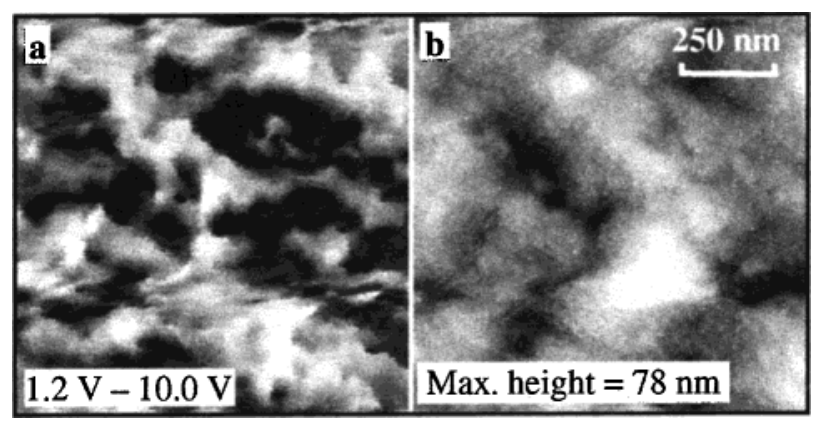

Figure 19. Chain extender: cis-but-2-ene-1,4-diol. Pull-off force (a) and topographic (b) images from a $1 \mu \mathrm{m} \times 1 \mu \mathrm{m}$ scan made at room temperature.

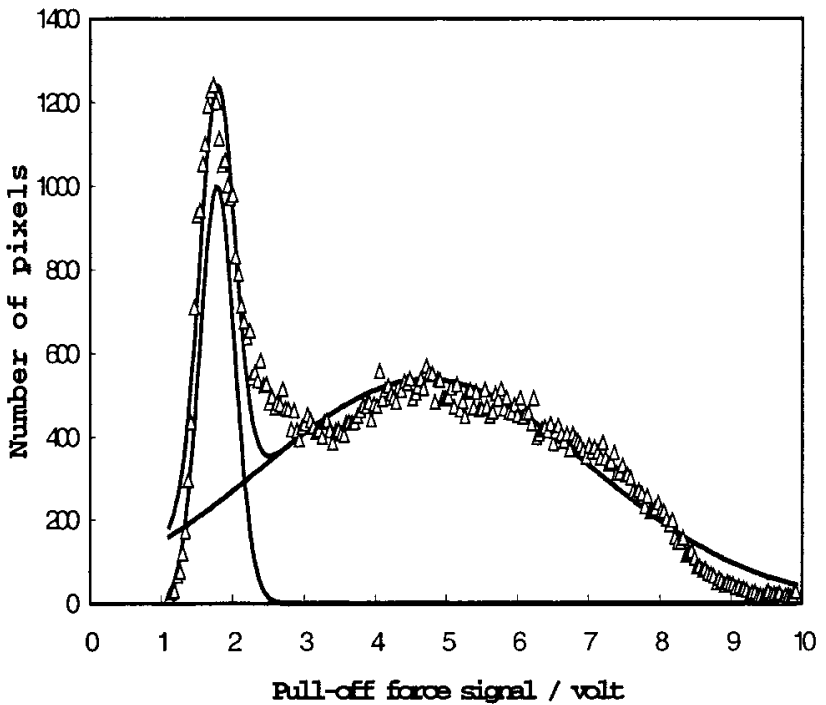

Figure 20. Chain extender: cis-but-2-ene-1,4-diol. Histogram showing the pull-off force distribution from the $1 \mu \mathrm{m} \times 1 \mu \mathrm{m}$ room-temperature scan in Figure 19. Results of Gaussian curve-fitting are shown.

(Figure 10) is consistent with this, as it shows that the glass transition finishes, on heating, at around $-36^{\circ} \mathrm{C}$. It is interesting that, although this scan has insufficient magnification to show the structure, the pull-off force measurement still shows the two-phase nature of the sample.

The topographic images show that roughly the same areas were scanned at the two temperatures. Minor topographic differences are, as before, apparent. These are again the result of a change in compliance rather than the cause of the change in adhesion-related contrast.

Figure 19 shows adhesion and topographic images resulting from a $1 \mu \mathrm{m} \times 1 \mu \mathrm{m}$ scan. There is an artifact, indicative of difficult scanning conditions, toward the end (bottom) of the pull-off force image. This was caused by the combination of a deep narrow valley, lying parallel to the raster direction, being bisected by the highest region in the scanned area. Consistent spatial resolution of adhesion properties was, however, maintained. The histogram of the pull-off force distribution shown in Figure 20 is from the $1 \mu \mathrm{m} \times 1 \mu \mathrm{m}$ scan. It shows that an area had been selected with a more even balance between the two phases. We again process the image so that each value of pull of force, and thus each corresponding pixel, is assigned to the phase that it most probably represents, and no gray area is allowed. This produces the result shown in Figure 21.

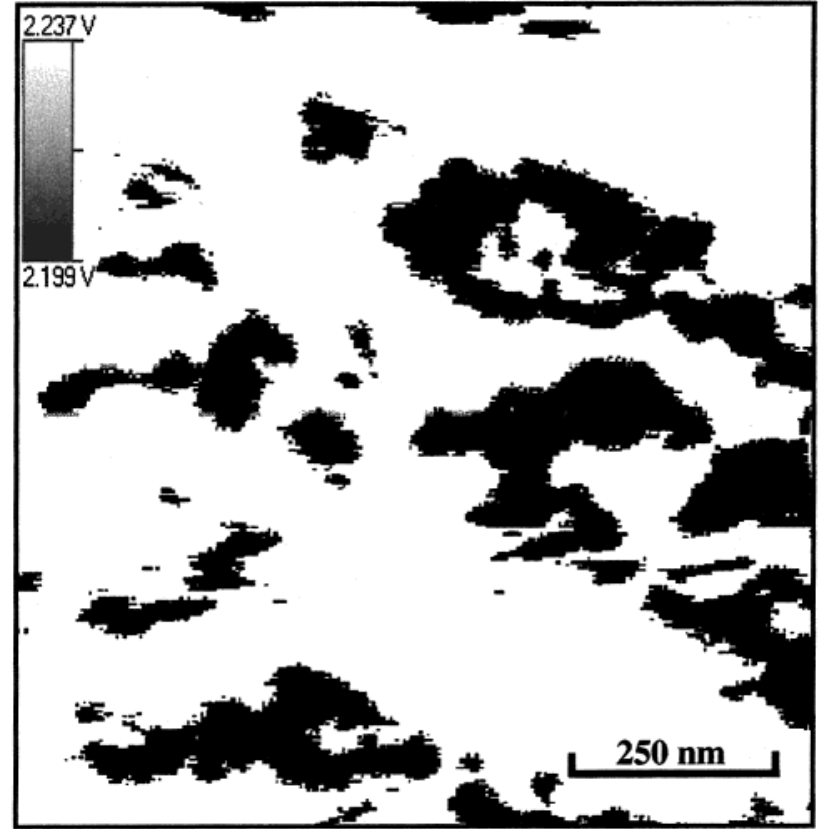

Figure 21. Chain extender: cis-but-2-ene-1,4-diol. The $1 \mu \mathrm{m}$ $\times 1 \mu \mathrm{m}$ room-temperature pull-off force image in Figure 19, processed using the curve fitting information in Figure 20. All measurements below the intersection voltage of the two populations $(2.2 \mathrm{~V})$ give black pixels, and all those above give white.

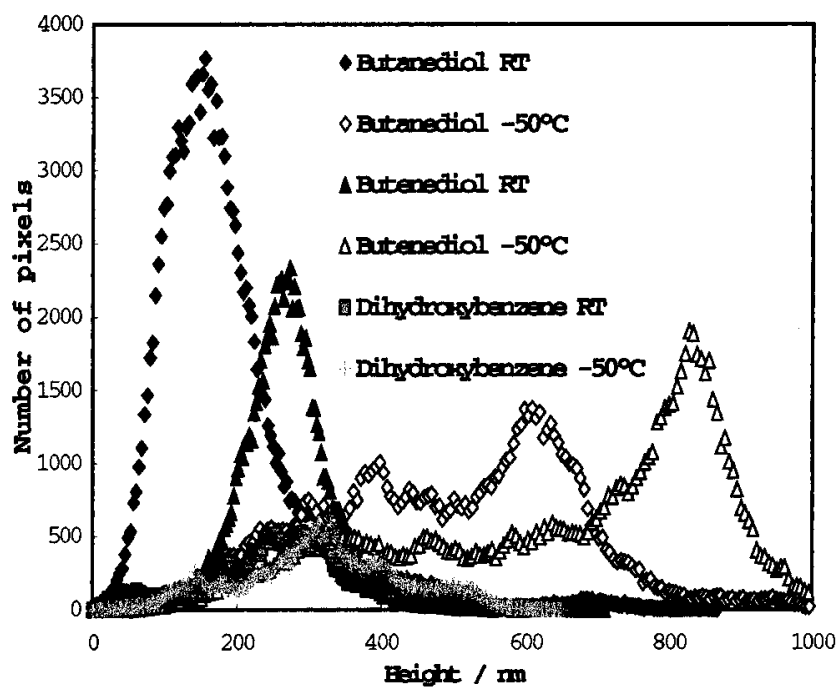

Figure 22. Topographic histograms of number of pixels vs height for all three SPU samples at room temperature and $-50^{\circ} \mathrm{C}$.

Overview. Overwhelming evidence that the features we observe in the pull-off force images of the SPUs do not stem from topographical contrast is provided in Figure 22. This shows topographical histograms from the three $10 \mu \mathrm{m} \times 10 \mu \mathrm{m}$ samples at both room temperature and $-50^{\circ} \mathrm{C}$. It can be checked whether topography is responsible for spatial variations in pulloff force for a particular sample by comparing the respective distributions of the two measurements. It is evident for all the materials that the change in height distribution with temperature, if anything, runs counter to the equivalent change in pull-off force distribution. On cooling, the distributions for the diol-extended materials move from being practically monomodal (compared with the bimodal pull-off force distributions) to being much broader and less symmetrical with a 
pronounced peak at high values. The two distributions for the material extended with 1,3-dihydroxybenzene show much more similarity to each other; both are relatively broad and monomodal. The room-temperature curve bears no correlation to the equivalent bimodal pull-off force distribution in Figure 12.

These results reveal a morphology that is far removed from the widely accepted structural model of these materials, having phases an order of magnitude larger than that of individual hard and soft segment domains. ${ }^{33-48}$ If the results indicate real morphology, then we must be detecting structures, whose growth results from the cooperative behavior of a large number of individual hard or soft domains. If the hard and soft segment domains present at the surface reflect bulk phases, then the nature and size of the individual segmented copolymer molecules dictate that the hard phases must contain a high proportion of soft segment material, and vice versa. It is unclear as to what mechanism or structural geometry could account for this behavior. It is likely that the surface of a phase differs markedly from its interior. It seems plausible, therefore, that the two individual bulk phases could consist of the same proportions of hard- and soft-segment domains, while simultaneously exhibiting very different surface properties. Surface energy and, therefore, adhesion will be particularly dependent on which type of domain dominates the surface. The form of the samples makes this hypothesis more likely. All were free surfaces imaged in the as-cast condition. Had they been microtomed sections, for example, the images would have been dependent on the "bulk" mechanical properties of individual phases. It is indeed possible that highmagnification scans on such samples could distinguish between the bulk and the surface. Thin films cast from solution could also be expected to produce very different results. In addition to any effect that this may have on the structure of the bulk material, it has been shown that a sub-nanometer soft segment-rich layer forms at the surface of such films. ${ }^{51,52}$ The possible existence of different surface layers on otherwise similar phases could explain the relative insensitivity of the indentation force measurements. Such ultrathin layers are less likely to produce significant differences in the local stiffness beneath the tip. That we are detecting a real phenomenon is supported by the reproducibility of the results. A large number of scans were carried out for each material, and the change in properties at different temperatures was consistent, while consecutive scans of the same area would invariably produce the same morphology.

\section{Conclusions}

The ability to carry out PFM experiments at temperatures as low as $-50^{\circ} \mathrm{C}$ and as high as $200^{\circ} \mathrm{C}$ has been demonstrated as a practicable method of carrying out microthermal analysis of materials. Furthermore, variable temperature PFM has proved to be a potentially powerful technique for characterizing the morphology of heterogeneous polymer systems. The adhesion-related pull-off force measurement has been shown to be much more sensitive to changes in surface properties than the stiffness-related indentation force. Our results for the PS-PMMA system demonstrate that, to facilitate absol ute comparisons between different sets of data, some form of reliable calibration procedure is required for the pull-off force measurement. In the absence of such a calibration procedure, meaningful conclusions may still be drawn from trends that occur as a function of temperature. In analyzing such trends it is important to consider that, at a given temperature, single phases give an approximately Gaussian distribution of pull-off force, and a single peak is observed regardless of temperature changes. Different polymers may show different trends in the relationship between the mean value and form of their pull-off force distributions and temperature. These trends may serve to identify phases in blends.

The analysis of histograms that show the intensity distribution of pull-off force results can provide a powerful tool to aid the interpretation of images and, furthermore, is essential in the construction of more meaningful images. This is applicable to all AFM techniques that are based on the measurement of a physical property. The fitting of Gaussian peaks to these histograms may serve to indicate how many phases are present, but caution must be used in interpreting this type of data. Where a surface consists of two or more phases having overlapping property distributions, it is impossible to achieve a complete separation of the phases in any image constructed from spatial variations in that property. It is possible, however, that established data and image analysis techniques will facilitate a more quantitative interpretation of the multimodal histograms that multiple phase materials have been shown to produce. This will, in turn, enable more accurate and useful images to be constructed. It has been shown that pull-off force images may be affected by the three-dimensional (subsurface) structure of a material, and this can manifest itself in a loss of edge definition or the detection of erroneous interphases. This is true even for materials in which a completely phaseseparated morphology exists and theindividual property distribution curves show no overlap.

Our work on the PS-PMMA blend shows that the pull-off force exhibited by poly (methyl methacrylate) is relatively insensitive to changes in temperature, whereas polystyrene exhibits a large step increase above its $\mathrm{T}_{\mathrm{g}}$. Although this allows the phase-separated morphology of this system to be characterized, before the technique can be applied more generally as a characterization tool, further investigation of the factors influencing the pulloff force and its relationship with temperature is required. These principally indude the type of polymer (amorphous or semicrystalline, polar or nonpolar, etc.) and molecular weight distribution. The effects of instrument variables, such as the frequency and amplitude of modulation, the set point (maximum compressive force), and probe geometry, also warrant further investigation.

We have shown that, at room temperature, PFM is able to produce high-contrast images showing the phaseseparated morphology of segmented polyurethanes. The results indicate that these materials have a complex structure, with phases an order of magnitude larger than the domain size usually obtained using other techniques, notably SAXS. Further work is clearly required to establish the nature of the morphology revealed by PFM and its relationship with that of individual hard- and soft-segment domains. In particular, it may be the case that the presence of phase separation at different scales is indicative of a fractal structure. 
Acknowledgment. The authors are grateful for the valuable support for this work provided by TA Instruments Inc. and the United Kingdom Engineering and Physical Sciences Research Council (EPSRC).

\section{References and Notes}

(1) Krotil, H. U.; Stifter, T.; Waschipky, H.; Weishaupt, K.; Hild S.; Marti, O. Surf. Interface Anal. 1999, 27, 336.

(2) Weilandt, E.; Hild, S.; Marti, O. Meas. Sci. Technol. 1997, 8, 1333.

(3) Miyatani, T.; Horii, M.; Rosa-Zeiser, A.; Fujihira, M.; Marti, O. Appl. Phys. Lett. 1997, 71, 2632.

(4) Sheiko, S. S.; Möller, M.; Cantow, H.-J .; Magonov, S. N Polym. Bull. 1993, 31, 693.

(5) Wawkuschewski, A.; Crämer, K.; Cantow, H.-J .; Magonov, S. N. UItramicroscopy 1995, 58, 185.

(6) García, R.; Tamayo, J .; San Paulo, A. Surf. Interface Anal. 1999, 27, 312.

(7) Bar, G.; Thomann, Y.; Whangbo, M.-H. Langmuir 1998, 14 1219.

(8) Bar, G.; Brandsch, R.; Whangbo, M.-H. Surf. Sci. Lett. 1999 436, L715.

(9) Wang, L. Surf. Sci. 1999, 429, 178.

(10) Bar, G.; Brandsch, R.; Whangbo, M.-H. Surf. Sci. Lett. 1999 422, L 192.

(11) Bar, G.; Brandsch, R.; Whangbo, M.-H.Surf. Sci. Lett. 1998 411, L802.

(12) Maganov, S. N.; Elings, V.; Whangbo, M.-H. Surf. Sci. Lett. 1997, 375, L 385.

(13) Li, F. B.; Thompson, G. E.; Newman, R. C. Appl. Surf. Sci. 1998, 126, 21

(14) Mizes, H. A.; Lo, K.-G.; Miller, R.J .; Ahuja, S. K.; Grabowski, E. F. Appl. Phys. Lett. 1991, 59, 2901.

(15) Brown, M. E. Introduction to Thermal Analysis; Kluwer Academic Publishers: Dordrecht, 1988.

(16) Hammiche, A.; Pollock, H. M.; Reading, M.; Song, M. J . Vac Sci. Technol. B: Microel ectron. Nanostruct. 1996, 14, 1486.

(17) Hammiche, A.; Reading, M.; Pollock, H. M.; Song, M.; Hourston, D. J. Rev. Sci. Instrum. 1996, 67, 4268.

(18) Price, D. M.; Reading, M.; Caswell, A.; Hammiche, A.; Pollock, H. M. Eur. Microsc. Anal. 1998, 65, 17.

(19) Pollock, H. M.; Hammiche, A.; Song.; Hourston, D. J .; Reading, M. J . Adhes. 1998, 67, 217.

(20) Price, D. M.; Reading, M.; Lever, T.J . J . Therm. Anal. Calor. 1999, 56, 673

(21) Price, D. M.; Reading, M.; Hammiche, A.; Pollock, H. M.; Branch, M. G. Thermochim. Acta 1999, 332, 143.

(22) Oulevey, F.; Burnham, N. A.; Gremaud, G.; Kulik, A. J .; Pollock, H. M.; Hammiche, A.; Reading, M.; Song, M.; Hourston, D. J . Polymer 2000, 41, 3087.

(23) Berger, C. E. H.; van der Werf, K. O.; Kooyman, R. P. H.; de Grooth, B. G.; Greve, J . Langmuir 1995, 11, 4188.
(24) Frisbie, C. D.; Rosznay, L. F.; Noy, A.; Wrighton, M. S.; Lieber, C. M. Science 1994, 265, 2071.

(25) Akari, S.; Horn, D.; Keller, H. Adv. Mater. 1995, 7, 594.

(26) Murray, A.; Lever, T. J .; Reading, M.; Price, D. M. Mater. World 1998, 6, 615.

(27) Reading, M.; Price, D. M.; Pollock, H. M.; Hammiche, A.; Murray, A. Am. Lab. 1999, 31, 13.

(28) Tsukruk, V. V.; Huang, Z. Polymer 2000, 41, 5541.

(29) Godovsky, Y. K.; Magonov, S. N. Langmuir 2000, 16, 3549.

(30) Sykes, P. A. Ph.D. Thesis, Loughborough University, 1999.

(31) Sawyer, L. C.; Grubb, D. T. Polymer Microscopy; Chapman and Hall: New York, 1987.

(32) Eisenbach, C. D.; Ribbe, A.; Günter, C. Macromol. Rapid Commun. 1994, 15, 395.

(33) McLean, R. S.; Sauer, B. B. Macromolecules 1997, 30, 8314

(34) Clayden, N. J .; Nijs, C.; Eeckhart, G. Macromolecules 1998, $31,7820$.

(35) Valenkar, S.; Cooper, S. Macromolecules 1998, 31, 9181.

(36) Chang, S. L.; Yu, T. L.; Huang, C. C.; Chen, W. C.; Linliu, K.; Lin, T. L. Polymer 1998, 39, 3479.

(37) Li, Y.; Ren, Z.; Zhao, M.; Yang, H.; Chu, B. Macromolecules 1993, 26, 612

(38) Koberstein, J . T.; Galambos, A. F.; Leung, L. M. Macromolecules 1992, 25, 6195

(39) Koberstein, J . T.; Galambos, A. F.; Leung, L. M. Macromolecules 1992, 25, 6205

(40) Xu, M.; Macknight, W. J .; Chen-Tsai, C. T. Y.; Thomas, E. L. Polymer 1987, 28, 2183.

(41) Li, Y.; Gao, T.; Chu, B. Macromolecules 1991, 25, 1737.

(42) Desper, C. R.; Schneider, N. S.; J asinsky, J. P.; Lin, J . S. Macromolecules 1987, 18, 2755.

(43) Koberstein, J. T.; Stein, R. S. Polymer 1984, 25, 171.

(44) Koberstein, J. T.; Stein, R. S. J . Polym. Sci., Polym. Phys. Ed. 1983, 21, 1439.

(45) Wilkes, G. L.; Samuels, S. L.; Crystal, R. J . Macromol. Sci. Phys. B 1974, 10, 203.

(46) Samuels, S. L.; Wilkes, G. L. Polym. Lett. 1971, 9, 761.

(47) Samuels, S. L.; Wilkes, G. L. J . Polym. Sci. Symp. 1973, 43, 149.

(48) Wilkes, G. L.; Yusek, C. S. J . Macromol. Sci. Phys. B 1973, 7, 157.

(49) Reading, M. Trends Polym. Sci. 1993, 1, 248.

(50) Reading, M.; Haines, P. J . In Thermal Methods of Analysis: Principles, Applications and Problems; Haines, P. J ., Ed. Blackie: London, 1995; pp 123-160.

(51) Shard, A. D.; Davies, M. C.; Tendler, S. J . B.; J ackson, D. E.; Lan, P. N.; Schacht. E.; Purbrick, M. D. Polymer 1995, 36, 775 .

(52) Hasegawa, H.; Hashimoto, T. Polymer 1992, 33, 475. MA0002040 